\title{
A Systematic Review of Human Infections by Pseudomonas mendocina
}

\author{
Petros Ioannou* (D) and Georgios Vougiouklakis \\ Department of Internal Medicine \& Infectious Diseases, University Hospital of Heraklion, \\ 71500 Heraklion, Crete, PC, Greece; billahem@hotmail.com \\ * Correspondence: p.ioannou@med.uoc.gr; Tel.: +30-2810-392-728; Fax: +30-2810-392-359
}

Received: 19 March 2020; Accepted: 1 May 2020; Published: 3 May 2020

\begin{abstract}
Pseudomonas mendocina is a Gram-negative, rod-shaped, aerobic bacterium that belongs in the family Pseudomonadaceae and has been isolated from water and soil. Even though it is thought to cause infections quite rarely in humans, it can cause severe infections even in immunocompetent individuals. The aim of this study was to systemically review all cases of human infection by P. mendocina in the literature and describe their epidemiology, microbiology, antimicrobial susceptibility, treatment and outcomes. Thus, a systematic review of PubMed for studies providing epidemiological, clinical, microbiological as well as treatment data and outcomes of Pseudomonas mendocina infections was conducted. In total, 12 studies, containing data of 16 patients, were included. The commonest P. mendocina infections were infective endocarditis, central nervous system infections and skin and soft tissue infections (SSTIs). Fever was the main presenting symptom, while sepsis was evident in almost half the patients. Pseudomonas mendocina was susceptible to most antibiotics tested. Mortality was low in all different infection types. Third or fourth generation cephalosporins and quinolones are the commonest agents used for treatment, irrespectively of the infection site.
\end{abstract}

Keywords: Pseudomonas mendocina; endocarditis; meningitis; SSTI; bacteremia

\section{Introduction}

Pseudomonas mendocina is a Gram-negative, rod-shaped, aerobic bacterium that belongs in the family Pseudomonadaceae. It was first isolated from water and soil in Mendoza, Argentina in 1970, and was named after that [1]. Even though it is thought to cause infections quite rarely in humans, it can cause severe infections, such as infective endocarditis (IE) or central nervous system (CNS) infections, even in immunocompetent individuals [2,3]. The aim of this study was to systemically review all cases of human infection by P. mendocina in the literature and describe their epidemiology, microbiology, antimicrobial susceptibility, treatment and outcomes.

\section{Methods}

\subsection{Data Search}

For the conduction of this review, the Preferred Reporting Items for Systematic Reviews and Meta-Analyses (PRISMA) guidelines were adopted [4]. A search of PubMed MEDLINE with the following text-words: pseudomonas[tw] AND mendoc* $[\mathrm{tw}]$ was used for identification of eligible studies. Day of last search was 4 January 2020.

\subsection{Study Selection}

Studies were included in analysis if the following criteria were met: (1) published in English; (2) reporting data on clinical characteristics, microbiology, treatment and outcomes. From the analysis, 
studies with the following criteria were excluded: (1) secondary research studies (such as reviews), editorials and articles not reporting primary research results; (2) studies not in humans; (3) studies on colonization but not infection by P. mendocina; (4) studies not in English. Two investigators (PI, GV) used abstrackr [5] to independently review the titles and abstracts of the resulting references and also retrieved and rescreened the full text publications of potentially relevant articles. Study selection was based on consensus. Reference lists of the studies that were included were searched for relevant articles.

\subsection{Study Outcomes}

The primary study outcomes were to record: (a) the epidemiology and medical history of patients with P. mendocina infection and (b) the type of P. mendocina infections included in the literature. Secondary outcomes included recording: (a) clinical characteristics for different type of infections, (b) microbiological data on P. mendocina infections, (c) their treatment and (d) their outcomes.

\subsection{Data Extraction and Definitions}

Each eligible study was examined by two investigators (PI, GV) who also extracted the data. Extracted data included study type, country and year of publication; patient demographic data (gender and age); patient's relevant medical history (diagnosis of prosthetic cardiac valve, autoimmune disease, cancer or chronic kidney disease); data on infection and microbiology (predisposing factors, such as neutropenia or presence of a central venous catheter (CVC), isolated bacterial strains, infection site, presence of complications); antimicrobial susceptibility data, treatment of the infection; and outcomes (i.e., death or cure). Relation of death to the infection was reported according to the authors of the study. The recorded complications included any clinical deterioration or organ dysfunction that was considered by the authors of the study to be related to the P. mendocina infection. The quality of evidence of the outcomes of included studies was assessed using the Grading of Recommendations Assessment, Development and Evaluation (GRADE) [6].

\section{Results}

\subsection{Literature Search}

In total, 294 articles from PubMed were screened. After title and abstract review, 12 studies were selected for full text review. None of these studies were excluded. Hand screening of the included articles' references did not identify any additional studies. Thus, 12 studies met the inclusion criteria of the present study [2,3,7-16]. Figure 1 shows a graphical representation of the review process. 
Records excluded $(\mathrm{n}=282)$

Full text articles excluded $(n=0)$
Records identified through PubMed $(\mathrm{n}=294)$

Title and abstract screening $(n=294)$

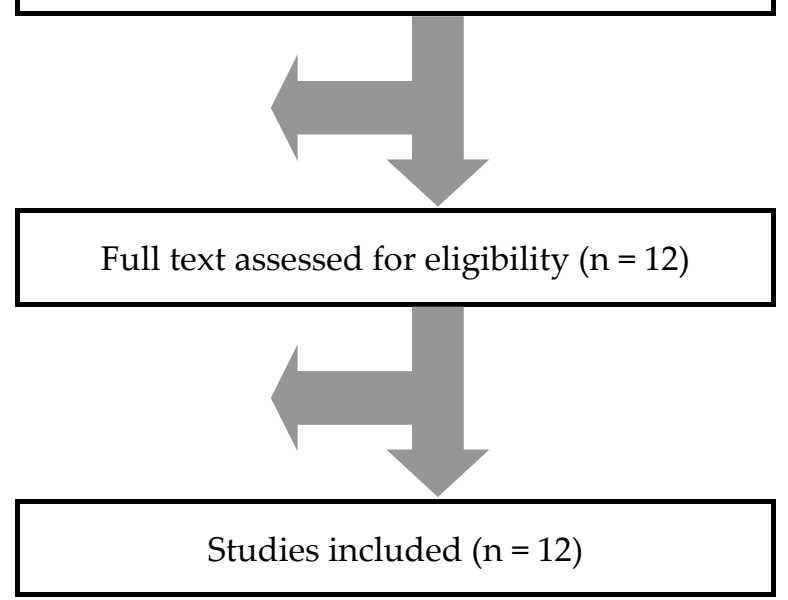

Figure 1. Preferred Reporting Items for Systematic Reviews and Meta-Analyses (PRISMA) flow diagram.

\subsection{Included Studies' Characteristics}

The 12 studies that were included in this analysis involved 16 patients in total. Among them, six were conducted in Asia, four in America and two in Europe. There were 10 case reports and two case series, thus, the overall quality of evidence that contributed to this systematic review was rated as low to very low [6].

\subsection{Epidemiology, Microbiology, Treatment and Outcomes of P. mendocina Infections}

Age of patients ranged from 22 to 86 years; the mean age was 53.5 years and $75 \%$ were male. The commonest infections were IE and CNS infections in $25 \%$ (four patients) each, skin and soft tissue infections (SSTIs) in 18.8\% (three patients), musculoskeletal infections and bacteremia (without IE) in $12.5 \%$ (two patients) and peritoneal dialysis-associated peritonitis in $6.3 \%$ (one patient). A concomitant infection was noted in $21.4 \%$ (three out of 14 cases). Fever was present in $70 \%$ (seven out of 10 cases), and sepsis in $44.4 \%$ (four out of nine cases). Resistance to ampicillin was noted in $80 \%$ (four out of five cases with available data), to co-trimoxazole in $33.3 \%$ (one out of three cases), to carbapenems in $10 \%$ (one out of 10 cases), and to third or fourth generation cephalosporins, aminoglycosides, quinolones, piperacillin-tazobactam and colistin in $0 \%$ ( 0 out of $11,10,7,6$ and 1 case, respectively). The commonest antibiotics for the treatment of $P$. mendocina infections were third or fourth generation cephalosporins in 53.3\% (eight out of 15 cases with available data), quinolones in $33.3 \%$ (five cases), aminoglycosides in $20 \%$ (three cases), carbapenems and colistin in $13.3 \%$ (two cases) each, and aminopenicillins, combination of piperacillin and tazobactam and co-trimoxazole in $6.7 \%$ (one case) each, while in 33.3\% (five cases), surgical treatment was also performed. Clinical cure was achieved in $93.3 \%$ of cases (14 out of 15 patients with available data) and overall mortality was $6.7 \%$ (one patient) but the mortality attributed directly to P. mendocina infection was $0 \%$. The characteristics of patients with P. mendocina infections are shown in Table 1. 
Table 1. Characteristics of 16 patients with infections by Pseudomonas mendocina: site of infection, antimicrobial resistance, treatment and outcomes. Values show cases among patients with available data.

\begin{tabular}{|c|c|}
\hline Characteristic & Value \\
\hline Male, n (\%) & 12 out of $16(75 \%)$ \\
\hline Age, mean $(+/-S D)$ in years & $53.5(19.9)$ \\
\hline \multicolumn{2}{|l|}{ Medical History } \\
\hline HIV infection, $\mathrm{n}(\%)$ & 1 out of $16(6.3 \%)$ \\
\hline Central venous catheter, n (\%) & 1 out of $16(6.3 \%)$ \\
\hline Previous antibiotic use, n (\%) & 1 out of $16(6.3 \%)$ \\
\hline No known predisposing factors, n (\%) & 7 out of $16(43.8 \%)$ \\
\hline \multicolumn{2}{|l|}{ Site of Infection } \\
\hline Infective endocarditis, $\mathrm{n}(\%)$ & 4 out of $16(25 \%)$ \\
\hline Central nervous system infection, $\mathrm{n}(\%)$ & 4 out of $16(25 \%)$ \\
\hline Skin and soft tissue infections, $\mathrm{n}(\%)$ & 3 out of $16(18.8 \%)$ \\
\hline Bacteremia (without endocarditis), n (\%) & 2 out of $16(12.5 \%)$ \\
\hline Musculoskeletal infections, n (\%) & 2 out of $16(12.5 \%)$ \\
\hline Peritoneal dialysis-associated peritonitis, $\mathrm{n}(\%)$ & 1 out of $16(6.3 \%)$ \\
\hline \multicolumn{2}{|l|}{ Data on Infection } \\
\hline Presence of fever, $\mathrm{n}(\%)$ & 7 out of $10(70 \%)$ \\
\hline Presence of sepsis, n (\%) & 4 out of $9(44.4 \%)$ \\
\hline \multicolumn{2}{|l|}{ Antimicrobial Resistance } \\
\hline Ampicillin resistance, $\mathrm{n}(\%)$ & 4 out of $5(80 \%)$ \\
\hline Co-trimoxazole resistance, $\mathrm{n}(\%)$ & 1 out of $3(33.3 \%)$ \\
\hline Carbapenem resistance, $\mathrm{n}(\%)$ & 1 out of $10(10 \%)$ \\
\hline Third or fourth generation cephalosporin resistance, n (\%) & 0 out of $11(0 \%)$ \\
\hline Aminoglycoside resistance, $\mathrm{n}(\%)$ & 0 out of $10(0 \%)$ \\
\hline Quinolone resistance, $\mathrm{n}(\%)$ & 0 out of $7(0 \%)$ \\
\hline Piperacillin-tazobactam resistance, n (\%) & 0 out of $6(0 \%)$ \\
\hline Colistin resistance, $\mathrm{n}(\%)$ & 0 out of $1(0 \%)$ \\
\hline \multicolumn{2}{|l|}{ Treatment of $P$. mendocina IE } \\
\hline Third or fourth generation cephalosporins, $\mathrm{n}(\%)$ & 8 out of $15(53.3 \%)$ \\
\hline Quinolones, $\mathrm{n}(\%)$ & 5 out of $15(33.3 \%)$ \\
\hline Aminoglycosides, n (\%) & 3 out of $15(20 \%)$ \\
\hline Carbapenems, n (\%) & 2 out of $15(13.3 \%)$ \\
\hline Colistin, n (\%) & 2 out of $15(13.3 \%)$ \\
\hline Piperacillin-tazobactam, n (\%) & 1 out of $15(6.7 \%)$ \\
\hline Aminopenicillins, n (\%) & 1 out of $15(6.7 \%)$ \\
\hline Co-trimoxazole, n (\%) & 1 out of $15(6.7 \%)$ \\
\hline \multicolumn{2}{|l|}{ Outcome } \\
\hline Clinical cure, n (\%) & 14 out of $15(93.3 \%)$ \\
\hline Deaths due to the infection, $\mathrm{n}(\%)$ & 0 out of $15(0 \%)$ \\
\hline Deaths overall, n (\%) & 1 out of $15(6.7 \%)$ \\
\hline
\end{tabular}

SD: standard deviation; HIV: human immunodeficiency virus. 


\subsection{Infective Endocarditis}

Among the 16 patients with P. mendocina infections, four (25\%) involved IE [3,7-9]. Among patients with IE, $75 \%$ were male (three out of four cases) and the mean age was 46 years. Patients with previous heart surgery represented $50 \%$ (two out of four cases); $25 \%$ had a prosthetic valve and $25 \%$ had ventricular septal defect, double-outlet right ventricle and pulmonary stenosis, while $75 \%$ of patients (three out of four cases) did not have any clear predisposing factor for developing IE. Bacteremia was present in 100\% (four cases). Presence of fever was noted in 100\% (four out of four patients), while $66.7 \%$ (two out of three patients with available data) were septic.

Resistance to ampicillin was $75 \%$ (three out of four cases), while resistance to aminoglycosides, third or fourth generation cephalosporins, piperacillin-tazobactam, quinolones, carbapenems, co-trimoxazole and colistin was $0 \%$. Presence of a concomitant infection was noted in $25 \%$ (one out of four cases), namely, an SSTI by another organism. For the treatment of P. mendocina IE, third or fourth generation cephalosporins, quinolones and aminoglycosides were used in $50 \%$ (two out of four cases), and carbapenems and the combination of piperacillin with tazobactam were used in $25 \%$ (two cases) each. Surgery was performed in 50\% (two cases): in 25\% (one case) mitral valve replacement and in $25 \%$ (one case) tricuspid valve repair. Among the three patients with available data, the median duration of symptoms was seven days, with a minimum of four and a maximum of 45 and the median duration of treatment was 49 days, with a minimum of 42 and a maximum of 91 . Clinical cure was achieved in 100\% (four out of four cases). Overall mortality was $0 \%$ (0 patients). The characteristics of patients with P. mendocina IE are shown in Table 2.

Table 2. Characteristics of four patients with infective endocarditis by Pseudomonas mendocina: antimicrobial resistance, treatment and outcomes. Values show cases among patients with available data.

\begin{tabular}{ll}
\hline \multicolumn{1}{c}{ Characteristic } & \multicolumn{1}{c}{ Value } \\
\hline Male, $\mathrm{n}(\%)$ & 3 out of $4(75 \%)$ \\
\hline Age, mean (+/- SD) in years & $46(16.7)$ \\
\hline \multicolumn{1}{c}{ Medical History } & 2 out of $4(50 \%)$ \\
\hline Previous cardiac surgery, $\mathrm{n}(\%)$ & 1 out of $4(25 \%)$ \\
\hline Prosthetic cardiac valve, $\mathrm{n}(\%)$ & 3 out of $4(75 \%)$ \\
\hline No known predisposing factors, $\mathrm{n}(\%)$ & 4 out of $4(100 \%)$ \\
\hline Concomitant bacteremia, $\mathrm{n}(\%)$ & \\
\hline \multicolumn{1}{c}{ Data on Infection } & $7(5-45)$ \\
\hline Duration of symptoms, median (IQR) in days & 4 out of $4(100 \%)$ \\
\hline Patients with fever, $\mathrm{n}(\%)$ & 2 out of $3(66.7 \%)$ \\
\hline Patients with sepsis, $\mathrm{n}(\%)$ & \\
\hline \multicolumn{1}{c}{ Antimicrobial Resistance } & 3 out of $4(75 \%)$ \\
\hline Ampicillin resistance, $\mathrm{n}(\%)$ & 0 out of $4(0 \%)$ \\
\hline Aminoglycoside resistance, $\mathrm{n}(\%)$ & 0 out of $3(0 \%)$ \\
\hline Third or fourth generation cephalosporin resistance, $\mathrm{n}(\%)$ & 0 out of $3(0 \%)$ \\
\hline Piperacillin-tazobactam resistance, $\mathrm{n}(\%)$ & 0 out of $3(10)$ \\
\hline Quinolone resistance, $\mathrm{n}(\%)$ & 0 out of $2(0 \%)$ \\
\hline Carbapenem resistance, $\mathrm{n}(\%)$ & 0 out of $1(0 \%)$ \\
\hline Co-trimoxazole resistance, $\mathrm{n}(\%)$ & 0 out of $1(0 \%)$ \\
\hline Colistin resistance, $\mathrm{n}(\%)$ & \\
\hline
\end{tabular}


Table 2. Cont.

\begin{tabular}{ll}
\hline \multicolumn{1}{c}{ Characteristic } & \multicolumn{1}{c}{ Value } \\
\hline \multicolumn{1}{c}{ Treatment of $\boldsymbol{P}$. mendocina Infections } \\
\hline Third or fourth generation cephalosporin, n (\%) & 2 out of $4(50 \%)$ \\
\hline Quinolones, n (\%) & 2 out of $4(50 \%)$ \\
\hline Aminoglycoside, $\mathrm{n}(\%)$ & 2 out of $4(50 \%)$ \\
\hline Piperacillin-tazobactam, n (\%) & 1 out of $4(25 \%)$ \\
\hline Carbapenems, $\mathrm{n}(\%)$ & 1 out of $4(25 \%)$ \\
\hline Surgical management, $\mathrm{n}(\%)$ & 2 out of $4(50 \%)$ \\
\hline Duration of treatment, median (IQR) in days & $49(42-82.3)$ \\
\hline \multicolumn{1}{c}{ Outcome } & 4 out of $4(100 \%)$ \\
\hline Clinical cure, $\mathrm{n}(\%)$ & 0 out of $4(0 \%)$ \\
\hline Deaths due to the infection, $\mathrm{n}(\%)$ & 0 out of $4(0 \%)$ \\
\hline Deaths overall, $\mathrm{n}(\%)$ & \\
\hline
\end{tabular}

SD: standard deviation; IQR: intraquartile range.

\subsection{CNS Infections}

Among the 16 patients with P. mendocina infections, four (25\%) involved CNS infections [2]. Among patients with CNS infections, 50\% were male (two out of four) and the mean age was 69.5 years. Among these infections, $75 \%$ (three out of four) were hospital acquired and $25 \%$ were community acquired, while 50\% (two out of four patients) did not have any clear predisposing factors for P. mendocina infection.

Treatment of P. mendocina CNS infections included third or fourth generation cephalosporins in $75 \%$ (three out of four cases), and a carbapenem was used in 25\% (one case). Clinical cure was achieved in $100 \%$ (four out of four cases) and overall mortality was $0 \%$. The characteristics of patients with P. mendocina CNS infections are shown in Table 3.

Table 3. Characteristics of four patients with central nervous system infections by Pseudomonas mendocina: treatment and outcomes. Values show cases among patients with available data.

\begin{tabular}{|c|c|}
\hline Characteristic & Value \\
\hline Male, n (\%) & 2 out of $4(50 \%)$ \\
\hline Age, mean $(+/-S D)$ in years & $69.5(11.3)$ \\
\hline \multicolumn{2}{|l|}{ Medical History } \\
\hline Community acquired infection, $\mathrm{n}(\%)$ & 2 out of $4(50 \%)$ \\
\hline Hospital acquired infection, $\mathrm{n}(\%)$ & 2 out of $4(50 \%)$ \\
\hline No known predisposing factors, $\mathrm{n}(\%)$ & 2 out of $4(50 \%)$ \\
\hline \multicolumn{2}{|c|}{ Treatment of $P$. mendocina CNS Infection } \\
\hline Third or fourth generation cephalosporins, $\mathrm{n}(\%)$ & 3 out of $4(75 \%)$ \\
\hline Carbapenems, n (\%) & 1 out of $4(25 \%)$ \\
\hline \multicolumn{2}{|l|}{ Outcome } \\
\hline Clinical cure, n (\%) & 4 out of $4(100 \%)$ \\
\hline Deaths due to the infection, $\mathrm{n}(\%)$ & 0 out of $4(0 \%)$ \\
\hline Deaths overall, $\mathrm{n}(\%)$ & 0 out of $4(0 \%)$ \\
\hline
\end{tabular}

SD: standard deviation; CNS: central nervous system. 


\subsection{Miscellaneous Infections}

Other less frequent infections by P. mendocina included SSTIs [12,13] in 18.8\% (three out of 16 cases), bacteremia (without IE) [10,11] and musculoskeletal infections [14,15] in 12.5\% (two cases) each, and peritoneal dialysis-associated peritonitis [16] in $6.3 \%$ (one case).

\section{Discussion}

Pseudomonas aeruginosa is among the leading causes of hospital infections, being a cause of hospital acquired pneumonia, bacteremia and infections of the urinary tract, contributing to increasing hospital costs and mortality [17]. On the other hand, non-Pseudomonas aeruginosa strains are much less frequently reported in the literature, with some of them being relatively unknown, such as P. mendocina. This study summarizes the available information on epidemiology and clinical presentation, treatment and outcomes of infections by P. mendocina.

Overall, IE, CNS infections and SSTIs were the commonest infections noted, and most patients were young and male. Interestingly, in almost half the cases, no predisposing factor for P. mendocina infection was noted. In terms of antibiotic resistance, $P$. mendocina was highly resistant to ampicillin and had low levels of resistance to co-trimoxazole and carbapenems. Otherwise, resistance to third or fourth generation cephalosporins, aminoglycosides, quinolones, piperacillin-tazobactam and colistin was zero, even though there were some missing data from some studies; thus it could be that some cases of antibiotic resistance were missed, as would one expect, for example, with the case of carbapenem resistance, where concomitant resistance to piperacillin-tazobactam would reasonably be anticipated.

Considering the abovementioned antibiotic resistance data, it is of no surprise that the commonest regimens used for the treatment of $P$. mendocina infections were third or fourth generation cephalosporins and quinolones, in more than $30 \%$ of cases each, while aminoglycosides, carbapenems, colistin, piperacillin with tazobactam, aminopenicillins and co-trimoxazole were used in less than $20 \%$ of cases. Interestingly, to our knowledge, there are no data on antimicrobial resistance of P. mendocina; thus, this study is the first one to systematically report antimicrobial susceptibility data of $P$. mendocina, allowing for choosing appropriate treatment for those infections.

IE is the commonest $P$. mendocina infection reported in the literature. Previous cardiac surgery and presence of a prosthetic cardiac valve were very common in patients with P. mendocina IE, implicating these factors as potential risks. In terms of antibiotic resistance, ampicillin resistance was very high, while no resistance to other antibiotics was noted. Thus, for treatment of P. mendocina IE, beta-lactamic antibiotics and quinolones were the commonest antibiotics used, in combination with an aminoglycoside in most of the cases. Surgical management was chosen in almost half of the cases, a proportion higher than that in other studies $[18,19]$. Mortality was zero, remaining very low as compared to that caused by other micro-organisms reported in the literature [18,19].

P. mendocina CNS infections were equally as common as IE in the literature. Half the patients had a hospital acquired infection, with one of them having an external ventricular drainage device. Surprisingly, $50 \%$ of patients, namely, those that had a community acquired CNS infection, did not have an obvious predisposing factor for developing meningitis from this particular micro-organism. The mainstay of treatment included third or fourth generation cephalosporins and carbapenems, while clinical cure was achieved in all the cases. Mortality was zero. This is in vast contrast with the CNS infections caused by other micro-organisms, and even more specifically from P. aeruginosa, that carry significant mortality $[2,20,21]$.

This systematic review has some limitations. First of all, it consists of case series and case reports, which means that the results must be studied with caution, since case reports describe unusual manifestations, implying that the common ones could be underrepresented in such a systematic review. For example, it could be that many cases of P. mendocina bacteremias occur but are not published, even in immunocompetent patients, thus affecting the rank of these infections among others. However, this methodology was the only reasonable way to systematically study P. mendocina infections. If studies 
describing less than four patients had been excluded, only one study would have been left for inclusion with only four patients with CNS infections [2].

To conclude, P. mendocina is a Gram-negative bacterium known to mainly cause IE, CNS infections, SSTIs, bacteremias and musculoskeletal infections. Even though ampicillin resistance is high, it shows notable sensitivity to most other antibiotics. Physicians looking after patients at risk should familiarize themselves with these infections.

Author Contributions: P.I. conceived the idea and supervised the study; P.I. and G.V. performed the literature review and the data analysis, and wrote the draft. All authors have read and agreed to the published version of the manuscript.

Funding: This research received no external funding.

Conflicts of Interest: The authors declare no conflict of interest.

\section{References}

1. Palleroni, N.J.; Doudoroff, M.; Stanier, R.Y.; Solánes, R.E.; Mandel, M. Taxonomy of the aerobic pseudomonads: The properties of the Pseudomonas stutzeri group. J. Gen. Microbiol. 1970, 60, 215-231. [CrossRef] [PubMed]

2. Huang, C.R.; Lien, C.Y.; Tsai, W.C.; Lai, W.A.; Hsu, C.W.; Tsai, N.W.; Chang, C.C.; Lu, C.H.; Chien, C.C.; Chang, W.N. The clinical characteristics of adult bacterial meningitis caused by non-Pseudomonas (Ps.) aeruginosa Pseudomonas species: A clinical comparison with Ps. aeruginosa meningitis. Kaohsiung J. Med. Sci. 2018, 34, 49-55. [CrossRef] [PubMed]

3. Mert, A.; Yilmaz, M.; Ozaras, R.; Kocak, F.; Dagsali, S. Native valve endocarditis due to Pseudomonas mendocina in a patient with mental retardation and a review of literature. Scand. J. Infect. Dis. 2007, 39, 615-616. [CrossRef] [PubMed]

4. Moher, D.; Liberati, A.; Tetzlaff, J.; Altman, D.G.; PRISMA Group. Preferred reporting items for systematic reviews and meta-analyses: The PRISMA statement. Ann. Intern. Med. 2009, 151, 264-269, W64. [CrossRef]

5. Wallace, B.C.; Small, K.; Brodley, C.E.; Lau, J.; Trikalinos, T.A. Deploying an interactive machine learning system in an evidence-based practice center: Abstrackr. Proc. ACM Int. Health Inform. Symp. IHI 2012, 819-824. [CrossRef]

6. Guyatt, G.H.; Oxman, A.D.; Vist, G.E.; Kunz, R.; Falck-Ytter, Y.; Alonso-Coello, P.; Schünemann, H.J. GRADE: An emerging consensus on rating quality of evidence and strength of recommendations. BMJ 2008, 336, 924-926. [CrossRef]

7. Aragone, M.R.; Maurizi, D.M.; Clara, L.O.; Navarro Estrada, J.L.; Ascione, A. Pseudomonas mendocina, an environmental bacterium isolated from a patient with human infective endocarditis. J. Clin. Microbiol. 1992, 30, 1583-1584. [CrossRef]

8. Johansen, H.K.; Kjeldsen, K.; Høiby, N. Pseudomonas mendocina as a cause of chronic infective endocarditis in a patient with situs inversus. Clin. Microbiol. Infect. 2001, 7, 650-652. [CrossRef]

9. Rapsinski, G.J.; Makadia, J.; Bhanot, N.; Min, Z. Pseudomonas mendocina native valve infective endocarditis: A case report. J. Med. Case Rep. 2016, 10, 275. [CrossRef]

10. Gani, M.; Rao, S.; Miller, M.; Scoular, S. Pseudomonas Mendocina Bacteremia: A Case Study and Review of Literature. Am. J. Case Rep. 2019, 20, 453-458. [CrossRef]

11. Nseir, W.; Taha, H.; Abid, A.; Khateeb, J. Pseudomonas mendocina sepsis in a healthy man. ISR Med. Assoc. J. 2011, 13, 375-376. [PubMed]

12. Almuzara, M.; Montaña, S.; Carulla, M.; Sly, G.; Fernandez, J.; Hernandez, M.; Moriano, A.; Traglia, G.M.; Bakai, R.; Ramirez, M.S. Clinical cases of VIM-producing Pseudomonas mendocina from two burned patients. J. Glob Antimicrob. Resist. 2018, 14, 273-274. [CrossRef] [PubMed]

13. Chiu, L.Q.; Wang, W. A case of unusual Gram-negative bacilli septic arthritis in an immunocompetent patient. Singapore Med. J. 2013, 54, e164-e168. [CrossRef] [PubMed]

14. Howe, T.S.; Ehrlich, G.D.; Koh, J.S.; Ng, A.C.; Costerton, W. A case of an atypical femoral fracture associated with bacterial biofilm-pathogen or bystander? Osteoporos. Int. 2013, 24, 1765-1766. [CrossRef]

15. Chi, C.Y.; Lai, C.H.; Fung, C.P.; Wang, J.H. Pseudomonas mendocina spondylodiscitis: A case report and literature review. Scand. J. Infect. Dis. 2005, 37, 950-953. [CrossRef] 
16. Jerónimo, T.M.; Guedes, A.M.; Stieglmair, S.; Guerreiro, R.; Laranjo, C.; Bernardo, I.; Neves, P.L. Pseudomonas mendocina: The first case of peritonitis on peritoneal dialysis. Nefrologia 2017, 37, 647-649. [CrossRef]

17. Sievert, D.M.; Ricks, P.; Edwards, J.R.; Schneider, A.; Patel, J.; Srinivasan, A.; Kallen, A.; Limbago, B.; Fridkin, S. National Healthcare Safety Network (NHSN) Team and Participating NHSN Facilities. Antimicrobial-resistant pathogens associated with healthcare-associated infections: Summary of data reported to the National Healthcare Safety Network at the Centers for Disease Control and Prevention, 2009-2010. Infect. Control Hosp. Epidemiol. 2013, 34, 1-14.

18. Papakonstantinou, P.E.; Samonis, G.; Andrianaki, A.M.; Christofaki, M.; Dimopoulou, D.; Papadakis, J.; Gikas, A.; Kofteridis, D.P. Epidemiology, Microbiological and Clinical Features, Treatment, and Outcomes of Infective Endocarditis in Crete, Greece. Infect. Chemother. 2018, 50, 21-28. [CrossRef]

19. Giannitsioti, E.; Skiadas, I.; Antoniadou, A.; Tsiodras, S.; Kanavos, K.; Triantafyllidi, H.; Giamarellou, H. Hellenic Endocarditis Study Group. Nosocomial vs. community-acquired infective endocarditis in Greece: Changing epidemiological profile and mortality risk. Clin. Microbiol. Infect. 2007, 13, 763-769. [CrossRef]

20. El Bcheraoui, C.; Mokdad, A.H.; Dwyer-Lindgren, L.; Bertozzi-Villa, A.; Stubbs, R.W.; Morozoff, C.; Shirude, S.; Naghavi, M.; Murray, C.J.L. Trends and Patterns of Differences in Infectious Disease Mortality Among US Counties, 1980-2014. JAMA 2018, 319, 1248-1260. [CrossRef]

21. Tzanakaki, G.; Mastrantonio, P. Aetiology of bacterial meningitis and resistance to antibiotics of causative pathogens in Europe and in the Mediterranean region. Int. J. Antimicrob. Agents 2007, 29, 621-629. [CrossRef] [PubMed]

(C) 2020 by the authors. Licensee MDPI, Basel, Switzerland. This article is an open access article distributed under the terms and conditions of the Creative Commons Attribution (CC BY) license (http://creativecommons.org/licenses/by/4.0/). 